\section{Have, Therefore I Love: Status Quo Preference in Mate Choice}

\author{
Gul Gunaydin'(D), Emre Selcuk², Cansu Yilmaz², \\ and Cindy Hazan ${ }^{3}$
}

Personality and Social Psychology Bulletin

$1-12$

(C) 2017 by the Society for Personality and Social Psychology, Inc Reprints and permissions: sagepub.com/journalsPermissions.nav DOI: $10.1177 / 0146167217746339$ pspb.sagepub.com

@SAGE

\begin{abstract}
Decades of research indicate that individuals adhere to existing states ("status quo bias") and value them more ("endowment effect"). The present work is the first to investigate status quo preference within the context of trade-offs in mate choice. Across seven studies (total $N=1,567$ ), participants indicated whether they would prefer remaining with a current partner possessing a particular set of traits (e.g., high trustworthiness, low attractiveness) or switching to an alternative partner possessing opposite traits. Preference for a given trait was highest when the individual representing the status quo (one's romantic partner or an interaction partner) possessed that trait. Concerns about hurting the partner, ambiguity avoidance, and biased construal of the partner and the alternative predicted status quo preference and disapproval of the current partner by network members eliminated this effect. These findings indicate that when it comes to matters of the heart, we tend to love what we currently have.
\end{abstract}

\title{
Keywords
}

status quo bias, endowment effect, decision making, romantic relationships, mate-choice trade-offs

Received March 16, 2017; revision accepted November 13, 2017

Decades of research have investigated how and why we make important decisions in our lives. Among the lifechanging decisions we face is choosing "the one" (Hazan \& Campa, 2013). Despite romantic notions of a "perfect soulmate," no partner is objectively perfect. Mate selection involves making trade-offs between alternative partners with different vices and virtues. For example, one alternative might be highly trustworthy but not very attractive, whereas another might be highly attractive but seemingly untrustworthy. In a number of studies, relationship scientists have investigated which characteristics individuals prefer when mate choice involves such tradeoffs (Fletcher, Tither, O’Loughlin, Friesen, \& Overall, 2004; N. P. Li, Bailey, Kenrick, \& Linsenmeier, 2002). In all of these studies, the choice offered was between two new alternatives. But, what if one of the alternatives is the current partner? In the present research, we studied mate choice trade-offs when the current partner is conceptualized as the status quo (i.e., the existing state of affairs). This novel conceptualization integrates two rich and diverse literatures - namely, decision making and relationship science-that heretofore have had very little cross talk (Joel, MacDonald, \& Plaks, 2013) and offers a new window into understanding why individuals persist in current relationships.

\section{Status Quo Preference in Trading Off Mate Qualities}

Do individuals respond differently to trade-offs in key mate qualities when the decision entails staying with a current partner (i.e., the status quo) versus switching to an alternative? On one hand, one could expect qualities that are preferred in a potential partner to be impervious to the presence of a status quo or lack thereof. It is theorized that individuals have a fairly clear conception of what they ideally desire in potential mates and that they use these preferences as a benchmark to evaluate current relationships (Fletcher \& Simpson, 2000). Supporting this idea, characteristics desired in an ideal mate predicted romantic interest following a speed dating event ( $\mathrm{Li}$ et al., 2013; but see Eastwick \& Finkel, 2008) and relationship initiation in real life (Campbell, Chin, \& Stanton, 2016). Moreover, the extent to which

\footnotetext{
'Bilkent University, Ankara, Turkey

${ }^{2}$ Middle East Technical University, Ankara, Turkey

${ }^{3}$ Cornell University, Ithaca, NY, USA

Corresponding Author:

Gul Gunaydin, Department of Psychology, Bilkent University,

HI35-A Bilkent, 06800 Ankara, Turkey.

Email: gulgunaydin@bilkent.edu.tr
} 
perceptions of current partners matched individuals' ideal mate preferences predicted greater relationship satisfaction (Campbell, Simpson, Kashy, \& Fletcher, 2001; Fletcher, Simpson, \& Thomas, 2000) and lower likelihood of breakup (Eastwick \& Neff, 2012; Fletcher et al., 2000; Hammond \& Overall, 2014), suggesting that individuals evaluate their relationships by comparing them with fairly stable ideal standards. Therefore, an ideal standards account would predict that preference for a given characteristic would be the same regardless of whether or not the current partner (i.e., the status quo) has that characteristic.

On the other hand, there is evidence supporting an opposing view. Research on status quo preference has repeatedly demonstrated that individuals are more likely to stick with existing states (status quo bias; E. J. Johnson \& Goldstein, 2003; Samuelson \& Zeckhauser, 1988) and ascribe greater value to them (endowment effect; Kahneman, Knetsch, \& Thaler, 1991; Thaler, 1980). Current partners, who represent the status quo in romantic relationships, may be no exception. It is possible that individuals show greater preference for an existing partner's characteristics, particularly when trying to resolve trade-offs in mate choice. Individuals compare the status quo with alternatives on each and every relevant characteristic and switch to a new alternative only when it surpasses the status quo on all fronts (Masatlioglu \& Ok, 2005). Therefore, when an alternative is not superior to one's current romantic partner on all characteristics (i.e., the mate selection decision involves trade-offs), the status quo would prevail. According to a status quo preference account then, preference for a given characteristic (e.g., trustworthiness) would be greater when one's current partner (i.e., the status quo) has that characteristic than when the alternative has that characteristic or when the choice is made in the absence of a status quo (i.e., the individual does not have a current partner). To date, no study has investigated this possibility.

\section{Mechanisms Underlying Status Quo Preference}

If the presence of a status quo indeed affects preference for mate qualities, what underlies this effect? Decision scientists have proposed that giving up advantages of the status quo and acquiring disadvantages of the alternative are perceived as potential losses, whereas giving up disadvantages of the status quo and acquiring advantages of the alternative are perceived as gains. Because individuals are loss averse, losses associated with changing the status quo loom larger than gains (Kahneman et al., 1991), which in turn leads to a more favorable construal of the status quo (Moshinsky \& Bar-Hillel, 2010). Moreover, the very existence of the status quo is taken as evidence by perceivers that it is superior to other options (existence bias; Eidelman \& Crandall, 2012). Indeed, when an option was presented as the status quo versus an alternative, individuals construed it more positively
(Davidai, Gilovich, \& Ross, 2012; Eidelman, Crandall, \& Pattershall, 2009; Moshinsky \& Bar-Hillel, 2010). Research in relationship science has shown a similar tendency to idealize current romantic partners (Gunaydin \& DeLong, 2015; Murray, Holmes, \& Griffin, 1996) and to derogate alternatives (D. J. Johnson \& Rusbult, 1989; Simpson, Lerma, \& Gangestad, 1990). Therefore, having a more favorable construal of the current romantic partner over alternatives may result in a status quo preference.

A loss aversion account would also predict that costs associated with leaving the current partner and switching to an alternative - such as effort required and uncertainties of starting a new relationship and the possibility of hurting the current partner-would motivate individuals to maintain the status quo. Individuals need to put in considerable effort to form and maintain a new relationship (Rusbult, 1983; Stafford \& Canary, 1991), which may deter them from changing the status quo (Dinner, Johnson, Goldstein, \& Liu, 2011; E. J. Johnson \& Goldstein, 2003). Starting a new relationship also entails uncertainties (Berger \& Calabrese, 1975; Joel et al., 2013), and motivation to avoid such uncertainties may increase reluctance to abandon the status quo. Finally, when contemplating a breakup, individuals may be concerned about being judged as cruel (Perilloux \& Buss, 2008) or hurting their partner's feelings (Joel, Teper, \& MacDonald, 2014) and hence show status quo preference.

\section{Boundary Conditions of Status Quo Preference}

If the presence of a status quo alters preference for mate characteristics as strongly as it does for choices in other life domains, are there any factors that may moderate this effect? According to a recent extension of the investment model (Agnew, Arriaga, \& Wilson, 2008), when one makes high past and potential future investments in a relationship, perceives good alternatives to an existing partner, experiences low relationship satisfaction, or believes that social network members disapprove of their current relationship, they experience lower commitment and hence are more likely to break up. Based on this model, factors that erode commitment to the current romantic partner might be expected to weaken status quo preference in mate choice. In the current research, we examined a common and potent source of influencenamely, social network approval. We often seek relationship advice from friends and family and at times they poke their noses into our love life without being asked (Buunk, Park, \& Dubbs, 2008; Sprecher, 2011). Moreover, approval of network members is an important predictor of commitment and the likelihood of breakup (Etcheverry \& Agnew, 2004; Sprecher \& Felmlee, 1992). Based on these findings, it is possible that if friends and family disapprove of the current partner and approve of an alternative partner, status quo preference might disappear. 


\section{Present Research}

The present studies investigated status quo preference when resolving trade-offs in key mate qualities and the possible mechanisms and boundary conditions of this effect. Responding to recent calls to integrate decision making and relationship literatures (Joel et al., 2013), the studies draw upon and integrate theory and methods from both literatures. Across seven studies (total $N=1,567$ ), participants indicated whether they would prefer remaining with a current partner (i.e., the status quo) possessing a particular set of traits (e.g., high trustworthiness, low attractiveness) or switching to an alternative possessing opposite traits (e.g., high attractiveness, low trustworthiness). In Studies 1 to 3, we investigated status quo preference using vignettes - a common and wellvalidated method in decision making (Hainmueller, Hangartner, \& Yamamoto, 2015) as well as mate selection research (Fletcher et al., 2004) that allows for tight experimental control. Vignettes used in each study involved a trade-off between two of the three dimensions found to be central to mate selection decisions - trustworthiness, attractiveness, and wealth (Fletcher, Simpson, Thomas, \& Giles, 1999). Study 2 investigated whether disapproval of the current partner by network members would moderate status quo preference in mate choice. Study 3 focused on potential theoretical mechanisms underlying status quo preferencenamely, effort and uncertainties involved in starting a new relationship, concerns about hurting the partner, and biased construal of the current partner's and the alternative's qualities. Finally, Study 4 examined status quo preference in an actual interpersonal decision made in the laboratory where the status quo is a newly encountered person.

Across all studies, we estimated sample sizes a priori based on statistical power analyses - using an online resource (http://biomath.info/power/chsq.htm) for chi-square tests (Studies 1-4) and G*Power (Faul, Erdfelder, Lang, \& Buchner, 2007) for logistic regression analyses (Study 3). For the online studies, we checked at the end of each day whether the number of participants who completed the survey exceeded the minimum sample size determined by power analyses and closed the surveys accordingly. For the laboratory study, we stopped data collection after exceeding the minimum sample size that was determined by power analysis. Statistical analyses were conducted after data collection for each study was completed. All data reported in this article are available from the Open Science Framework Database (https://osf.io/ne3ee/?view_only=61571b4fad8f4d 48930f003e7db48571).

\section{Study I: Trading Off a Romantic Partner With an Alternative}

\section{Method}

Participants. For Studies 1a, 1c, and 1d, the sample consisted of individuals affiliated with a university in Ankara, Turkey, who received an email invitation to participate in an online survey on a voluntary basis or for course credit. ${ }^{1}$ For Study $1 \mathrm{~b}$, the sample consisted of a community sample residing in the United States. The sample size to achieve .80 power at $p$ $<.05$ assuming a small effect (i.e., group proportions of .70 and .90) was estimated as 213 for each study.

Study Ia. Two hundred fifty-five participants started the survey, and 254 provided a response to the mate selection scenario (133 women, 85 men, 36 did not answer the question; age range 18-38 years; 100 were in a romantic relationship, 116 were single, 38 did not answer the question). ${ }^{2}$

Study Ib. Two hundred twenty-seven participants accessed the survey via Amazon's Mechanical Turk, and 222 provided a response to the mate selection scenario (134 women, 86 men, two other; age range $18-72$ years; 171 were in a romantic relationship, 51 were single).

Study Ic. Two hundred fifty-four participants started the survey, and 253 provided a response to the mate selection scenario (137 women, 86 men, 30 did not answer the question; age range 18-39 years; 101 were in a romantic relationship, 121 were single, 31 did not answer the question).

Study Id. Two hundred fifty-four participants started the survey, and all provided a response to the mate selection scenario (135 women, 80 men, 39 did not answer the question; age range 18-33 years; 107 were in a romantic relationship, 107 were single, 40 did not answer the question).

Procedures. In Study 1a, participants were asked to read a scenario and imagine themselves in the situation described in the scenario as vividly as possible. They were instructed to respond based not on a current romantic partner or even a previous partner but rather on the partner they were asked to imagine in the scenario. Participants then received descriptions of two individuals in counterbalanced order: one was attractive but untrustworthy, the other was trustworthy but unattractive. In the attractive partner condition, participants were asked to imagine that the attractive (but untrustworthy) individual was their romantic partner and that they met a trustworthy (but unattractive) alternative who showed romantic interest in them. The partner and the alternative were described as follows:

Imagine that you have been involved in a romantic relationship for 3 months and recently were introduced to a new person through mutual friends. You realize immediately that this alternative partner is romantically attracted to you. You find your partner (in this scenario) to be more physically attractive and you feel more physical chemistry. But you feel like your relationship sometimes takes a back seat for your partner and it is sometimes hard to get their attention or support when needed. In contrast, the alternative seems like a person who would understand and support relationship partners and who would 
value relationships. But the alternative is less physically attractive than your partner and there is much less physical chemistry between you.

Participants then indicated whether or not they would consider ending their current relationship to start a new relationship with the alternative by providing a "yes" or a "no" response. The order of response options (left vs. right) was counterbalanced across participants. In the trustworthy partner condition, characteristics of the partner and the alternative were reversed: the trustworthy (but unattractive) individual was described as the partner, and the attractive (but untrustworthy) individual was described as the alternative. In the no partner condition, participants were asked to imagine that they were currently not in a romantic relationship and to decide between two potential mates with the abovementioned qualities.

Procedures of Study 1b were identical to those of Study 1a except that this study did not include the no partner condition. Procedures of Study 1c and 1d too were identical to those of Study 1a except that in Study 1c, participants were asked to choose between a trustworthy but not wealthy individual and a wealthy but untrustworthy individual, and in Study 1d, participants were asked to choose between an attractive but not wealthy individual and a wealthy but unattractive individual (in the presence or absence of a status quo). Trustworthiness information used in Study 1c and attractiveness information used in Study 1d were identical to those in Study 1a. In both studies, the wealthy individual was described as coming from a high-income family and having their own savings and a good job, whereas the not wealthy individual was described as coming from a low-income family, not having much in savings, and searching for employment but not being able to find work.

\section{Results}

As shown in Table 1, results of all four studies revealed that preferences for mate qualities shifted in favor of the status quo (i.e., the current partner). ${ }^{3}$

Study Ia. Of participants who imagined that their current partner was attractive, a lower proportion preferred trustworthiness over attractiveness as compared with the trustworthy partner condition, $\chi^{2}(1)=24.144, p<.001$, contingency coefficient $(C)=.351,95 \%$ confidence interval $(\mathrm{CI})=[.228$, $.451]$, or the no partner condition, $\chi^{2}(1)=9.119, p=.003, C$ $=.228,95 \% \mathrm{CI}=[.076, .358]$.

Study Ib. Replicating findings of Study 1a, of participants who imagined that their current partner was attractive, a lower proportion preferred trustworthiness over attractiveness as compared with the trustworthy partner condition, $\chi^{2}(1)=17.978, p<.001, C=.274,95 \% \mathrm{CI}=[.158, .380]$.
Study Ic. Of participants who imagined that their current partner was wealthy, a lower proportion preferred trustworthiness over wealth as compared with the trustworthy partner condition, $\chi^{2}(1)=39.824, p<.001, C=.439,95 \% \mathrm{CI}=[.340$, $.518]$, or the no partner condition, $\chi^{2}(1)=22.223, p<.001, C$ $=.342,95 \% \mathrm{CI}=[.212, .451]$.

Study Id. Similarly, of participants who imagined that their current partner was wealthy, a lower proportion preferred attractiveness over wealth compared with the attractive partner condition, $\chi^{2}(1)=73.930, p<.001, C=.547,95 \% \mathrm{CI}=$ $[.487, .597]$, or the no partner condition, $\chi^{2}(1)=26.032, p<$ $.001, C=.364,95 \% \mathrm{CI}=[.241, .465]$.

\section{Study 2: Social Network Approval and Status Quo Preference}

Having demonstrated a strong effect of status quo information on mate choice across different mate qualities in the first four studies, next we investigated how social network approval would affect status quo preference. Network members - such as friends and family-exert a strong influence on whom we choose as mates (Sprecher, 2011). Therefore, we expected that greater preference for the current partner's traits observed in previous studies would disappear when friends and family disapprove of the current partner and approve of the alternative.

\section{Method}

Participants. To determine the sample size, we used proportions obtained in Study 1a (.39 and .76), which entailed a trade-off between trustworthiness and attractiveness. We wanted to make sure that we recruit in each social network condition (approved partner vs. disapproved partner vs. no approval information) at least 64 participants to replicate the Study 1a effect with $80 \%$ power, resulting in a total sample size of 192. The actual sample size exceeded this number, with 217 participants starting the survey and providing a response to the mate selection scenario (131 women, 86 men; age range 18 -29 years; 110 were in a romantic relationship, 105 were single, two did not answer the question).

Procedures. To create a trade-off between trustworthiness and attractiveness, Study 2 used the two scenarios from Study 1a that involved a choice between a current partner and an alternative. We also manipulated network approval of these two individuals. In the approved partner condition, participants were asked to imagine that their family and close friends approved of their current partner and thought that she or he was a good match for them. They were also asked to imagine that their family and close friends disapproved of the alternative and thought that she or he was not a good match for them. In the disapproved partner condition, these instructions were 
Table I. Preference for Mate Qualities Across Studies.

\begin{tabular}{|c|c|c|c|c|c|c|}
\hline Study: Preference & Experimental condition & $n$ & $\begin{array}{l}\text { Demonstrating } \\
\text { preference \% }\end{array}$ & $\chi^{2}, d f$ & $\begin{array}{l}\text { Contingency } \\
\text { coefficient }\end{array}$ & $95 \% \mathrm{Cl}$ \\
\hline \multirow{3}{*}{$\begin{array}{l}\text { Ia: Trustworthiness } \\
\text { over attractiveness }\end{array}$} & Trustworthy partner, attractive alternative & 87 & 75.9 & & & \\
\hline & Attractive partner, trustworthy alternative & 85 & 38.8 & $24.886 * * *, 2$ & .299 & {$[.200, .398]$} \\
\hline & No partner & 82 & 62.2 & & & \\
\hline \multirow{2}{*}{$\begin{array}{l}\text { Ib: Trustworthiness } \\
\text { over attractiveness } \\
\text { (U.S. replication) }\end{array}$} & Trustworthy partner, attractive alternative & 112 & 75.0 & 17.978***, I & .274 & {$[.158, .380]$} \\
\hline & Attractive partner, trustworthy alternative & 110 & 47.3 & & & \\
\hline \multirow{3}{*}{$\begin{array}{l}\text { Ic: Trustworthiness } \\
\text { over wealth }\end{array}$} & Trustworthy partner, wealthy alternative & 85 & 90.6 & & & \\
\hline & Wealthy partner, trustworthy alternative & 82 & 45.1 & $47.174 * * *, 2$ & .396 & {$[.300, .479]$} \\
\hline & No partner & 86 & 80.2 & & & \\
\hline \multirow{3}{*}{$\begin{array}{l}\text { Id: Attractiveness } \\
\text { over wealth }\end{array}$} & Attractive partner, wealthy alternative & 84 & 96.4 & & & \\
\hline & Wealthy partner, attractive alternative & 89 & 33.7 & $78.68 I^{* * *}, 2$ & .486 & {$[.426, .547]$} \\
\hline & No partner & 81 & 72.8 & & & \\
\hline \multirow[t]{6}{*}{$\begin{array}{ll}\text { 2: } & \text { Trustworthiness } \\
& \text { over attractiveness }\end{array}$} & $\begin{array}{l}\text { Baseline: Trustworthy partner, attractive } \\
\text { alternative }\end{array}$ & 38 & 89.5 & $19.819 * * *, 1$ & .457 & {$[.308, .568]$} \\
\hline & $\begin{array}{l}\text { Baseline: Attractive partner, trustworthy } \\
\text { alternative }\end{array}$ & 37 & 40.5 & & & \\
\hline & $\begin{array}{l}\text { Partner approved: Trustworthy partner, } \\
\text { attractive alternative }\end{array}$ & 36 & 77.8 & $23.702 * * *, 1$ & .500 & {$[.352, .605]$} \\
\hline & $\begin{array}{l}\text { Partner approved: Attractive partner, } \\
\text { trustworthy alternative }\end{array}$ & 35 & 20.0 & & & \\
\hline & $\begin{array}{l}\text { Partner disapproved: Trustworthy partner, } \\
\text { attractive alternative }\end{array}$ & 34 & 41.2 & $0.400,1$ & .075 & {$[.005, .298]$} \\
\hline & $\begin{array}{l}\text { Partner disapproved: Attractive partner, } \\
\text { trustworthy alternative }\end{array}$ & 37 & 48.6 & & & \\
\hline \multirow{2}{*}{$\begin{array}{l}\text { 3: } \text { Trustworthiness } \\
\text { over attractiveness }\end{array}$} & Trustworthy partner, attractive alternative & 157 & 67.5 & $38.056 * * *, 1$ & .327 & {$[.238, .4 \mid 2]$} \\
\hline & Attractive partner, trustworthy alternative & 161 & 32.9 & & & \\
\hline \multirow{2}{*}{$\begin{array}{l}\text { 4: Trustworthiness } \\
\text { over wealth }\end{array}$} & Trustworthy partner, wealthy alternative & 26 & 69.2 & $5.815^{*}, 1$ & .326 & {$[.071, .532]$} \\
\hline & Wealthy partner, trustworthy alternative & 23 & 34.8 & & & \\
\hline
\end{tabular}

Note. Each study entails a trade-off between two mate characteristics. Column 4 shows for each experimental condition the percentage of participants who preferred the first characteristic (e.g., trustworthiness) over the second characteristic (e.g., attractiveness) indicated in column I. Cl = confidence interval.

$* p=.016 . * * * p .001$.

reversed. Finally, in the no approval information condition, participants were given no information on social network approval of the current partner or the alternative.

\section{Results}

The status quo preference effect was replicated in the no approval information and approved partner conditions, with participants imagining that their current partner was trustworthy (vs. attractive), demonstrating a markedly higher preference for trustworthiness over attractiveness (see Table 1). However, social network disapproval of the current partner eliminated preference for the current partner's traits. That is, when friends and family disapproved of the partner and approved of the alternative, participants in the trustworthy partner condition no longer preferred trustworthiness over attractiveness as compared with participants in the attractive partner condition. ${ }^{4}$ These findings indicate that network disapproval of the current partner completely wiped out status quo preference in mate choice, consistent with prior work showing the profound role of network opinions in mate selection.

\section{Study 3: Mechanisms Driving Status Quo Preference}

In Study 3, we drew on both the decision making and mate selection literatures to explore potential causes of status quo preference in mate choice. We investigated whether prominent costs of ending the current relationship - namely, the effort required to switch to the alternative (Dinner et al., 2011), uncertainties of starting a new relationship (Berger \& Calabrese, 1975), and concerns about hurting the current partner (Perilloux \& Buss, 2008) — predict status quo preference. Therefore, we asked participants the extent to which these potential costs motivated their response to the mate choice scenario. We also investigated whether greater preference for 
partner traits could be explained by construal of choices (e.g., Eidelman et al., 2009)—specifically, construing the partner as possessing more favorable traits and the alternative as possessing relatively less favorable traits. To investigate this, we asked participants to judge the partner and the alternative on evaluative adjectives.

Finally, we sought to address potential alternative interpretations of our findings. When individuals are asked whether they prefer the status quo or the alternative, they might infer that the person who posed this question favors the status quo (Dinner et al., 2011; E. J. Johnson \& Goldstein, 2003; McKenzie, Liersch, \& Finkelstein, 2006). In our studies, question-posers are the researchers-which brings forth a potential alternative interpretation of our findings as resulting from experimenter demand. It is possible that participants thought that the researchers wanted them to favor a given set of traits when the current partner was described to possess those traits. It is also plausible that individuals showed preference for partner traits because they thought that most people in the same situation would show a similar preference, making it possible that willingness to conform to social norms might explain status quo preference (Dinner et al., 2011). In the current study, we sought to rule out that the observed effects might be due to experimenter demand or conformity to social norms. We also sought to address the alternative interpretation that preference for traits associated with the status quo observed in our studies might result from shallow processing of the scenarios. If so, one could expect that individuals who make their decision faster (and who therefore do not deeply consider the alternative) would be more likely to stick with the status quo. By measuring how long participants took to respond to the mate selection scenario, we sought to rule out this alternative interpretation.

\section{Method}

Participants. To conduct statistical power analysis, we assumed, based on results of Study 1a, that the probability of staying with the partner is .69. The sample size to detect a $10 \%$ increase in the probability of staying with the partner with .80 power at $p<.05$ was estimated as 310 . Five hundred twenty-five participants started the survey, and 318 completed all measures of interest for the current study (200 women, 118 men; age range 18-69 years; 151 were in a romantic relationship, 164 were single, three did not answer the question).

Procedures and materials. To create a trade-off between trustworthiness and attractiveness, Study 3 used the two scenarios from Study 1a that involved a choice between a current partner and an alternative. After indicating whether or not they would consider ending their current relationship to start a new relationship with the alternative, participants completed the measures below.
Experimenter demand. Following Dinner and colleagues (2011), we asked participants to indicate their agreement with the statement "I made my choice because I thought the researchers wanted me to select that option" (1 = strongly disagree to $7=$ strongly agree, $M=1.730, S D=1.168)$.

Conformity to social norms. Following Dinner and colleagues (2011), we asked participants to indicate their agreement with the statement "I made my choice because I thought most people would select that option" ( 1 = strongly disagree to $7=$ strongly agree, $M=3.022, S D=1.688)$.

Decision time. We measured the time (in seconds) it took participants to indicate their decision $(M=88.964, S D=$ 497.616). ${ }^{5}$

Effort required to switch to the alternative. Participants reported the extent to which their decision was influenced by "the time they have to invest in the new relationship" and "the effort they have to make for the new relationship" (1 $=$ not at all to $7=$ very). These two items were averaged to index perceived effort required to switch to the alternative ( $\alpha$ $=.828, M=3.642, S D=1.783)$.

Construal of the partner. Participants were asked to use their best guess to rate the current partner in the scenario on 10 traits distinct from attractiveness and trustworthiness (e.g., intelligent, confident; $1=$ not at all to $7=$ very) adapted from past work (Anderson, 1968). These judgments were averaged to index how favorably the partner was construed $(\alpha=.898, M=4.509, S D=1.164)$.

Construal of the alternative. Participants were asked to rate the alternative in the scenario on the same 10 traits. These judgments were averaged to index how favorably the alternative was construed $(\alpha=.878, M=4.249, S D=1.075)$.

Ambiguity avoidance. Participants reported the extent to which their decision was influenced by "uncertainties they might face if they started a relationship with the alternative" $(1=$ not at all to $7=$ very, $M=4.758, S D=1.902)$.

Concerns about hurting the partner. Participants reported the extent to which their decision was influenced by "wanting to avoid hurting their current partner" ( 1 = not at all to $7=$ very, $M=4.821, S D=2.018)$.

\section{Results}

Replicating the findings of previous studies, of participants who imagined that their current partner was trustworthy (vs. attractive), a higher proportion preferred trustworthiness over attractiveness (see Table 1).

Correlations between possible mechanisms and status quo preference $(0=$ preferring the alternative's traits, 
Table 2. Correlations Between Predictor Variables and Preference for the Current Romantic Partner.

\begin{tabular}{|c|c|c|c|c|c|c|c|c|c|}
\hline Variable & I & 2 & 3 & 4 & 5 & 6 & 7 & 8 & 9 \\
\hline I. Preference (partner vs. alternative) & & -.081 & -.082 & .058 & .023 & $.182^{* *}$ & $-.305 * * *$ & $.328 * * *$ & $.314 * * *$ \\
\hline 2. Experimenter demand & & & $.201 * * *$ & -.050 & .069 & -.037 & -.088 & .047 & .022 \\
\hline 3. Conformity to social norms & & & & -.055 & .075 & -.066 & -.016 & .027 & .097 \\
\hline 4. Decision time & & & & & -.068 & .050 & -.008 & .063 & .070 \\
\hline 5. Effort required to switch to the alternative & & & & & & -.021 & .020 & $.394 * * *$ & $.118^{*}$ \\
\hline 6. Construal of the partner & & & & & & & -.014 & $.133^{*}$ & $.179 * *$ \\
\hline 7. Construal of the alternative & & & & & & & & -.070 & -.077 \\
\hline 8. Ambiguity avoidance & & & & & & & & & $.293 * * *$ \\
\hline 9. Concerns about hurting the partner & & & & & & & & & \\
\hline
\end{tabular}

$* p<.05 . * * p<.01 . * * * p<.001$.

Table 3. Logistic Regression Model Predicting Preference for the Current Romantic Partner.

\begin{tabular}{|c|c|c|c|c|c|}
\hline Variable & B & SE & OR & $p$ value & $95 \% \mathrm{Cl}$ of $\mathrm{OR}$ \\
\hline Ambiguity avoidance & 0.322 & 0.075 & 1.380 & $<.001$ & {$[1.190,1.600]$} \\
\hline Concerns about hurting the partner & 0.256 & 0.070 & 1.292 & $<.001$ & {$[1.125,1.483]$} \\
\hline Construal of the partner & 0.290 & 0.126 & 1.337 & .021 & {$[1.044,1.71 \mathrm{I}]$} \\
\hline Construal of the alternative & -0.733 & 0.147 & 0.480 & $<.001$ & {$[0.360,0.640]$} \\
\hline Nagelkerke's $R^{2}$ & & .332 & & & \\
\hline
\end{tabular}

Note. $\mathrm{Cl}=$ confidence interval; $\mathrm{OR}=$ odds ratio.

$1=$ preferring the partner's traits) are provided in Table 2. To test for the unique role of each significant correlate, we conducted a logistic regression analysis with preference as the outcome variable and significant correlates of preference as the predictors. Higher ambiguity avoidance, higher concerns about hurting the partner, and having a favorable construal of the partner and a less favorable construal of the alternative were all uniquely associated with increased likelihood of preferring the partner's traits (Table 3 ).

These findings indicate that of the costs associated with ending the current relationship, only concerns about hurting the partner and uncertainties of the new relationship explain status quo preference in mate choice. Effort required to start a new relationship did not emerge as a significant correlate of mate preferences. Although speculative, it is possible that individuals underestimate the time and effort required for the new relationship and not consider it as a significant cost of ending the current relationship. Biased construal of the partner and the alternative also emerged as significant predictors of status quo preference, indicating that attributing virtues to the current partner and vices to the alternative might motivate individuals to maintain the status quo.

The alternative interpretations we considered failed to explain status quo preference. Time it took participants to make their decision did not significantly predict mate preferences, suggesting that shallow processing of the information provided in the vignettes cannot account for status quo preference in mate choice. Willingness to go along with the researchers' wishes or with what others would do also did not significantly predict mate preferences, suggesting that our findings cannot be explained by experimenter demand or conformity to social norms. It is, however, possible that participants were unaware (and hence unable to accurately report) that these factors affected their preferences. Future research should therefore use more indirect methods to rule out these alternatives.

\section{Study 4: Actual Preferences in the Laboratory}

Study 4 investigated whether status quo preference is observed for actual interpersonal decisions made in the laboratory. Toward this aim, we created a minimal situation that entailed a status quo, involving a trade-off between trustworthiness and wealth. Female participants had to choose between a newly encountered man whom they already selected as their interaction partner (i.e., the status quo) versus a new interaction partner whom they were given an opportunity to switch to (i.e., the alternative).

\section{Method}

Participants. To conduct statistical power analysis, we used estimates of effect size and proportions obtained in Study 1b, which involved a trade-off between trustworthiness and wealth. We aimed to achieve higher power in the current study because unlike previous studies, we tested the status quo preference under minimal conditions. The sample size to achieve .90 power at $p<.05$ assuming group proportions of .45 and .91 was estimated as 48 . Fifty-one single women (age range $=18-25$ years) completed the study. Two participants 
who selected one of the filler profiles (see below) were excluded, leaving a final analytic sample of 49 individuals.

\section{Procedures and materials}

Profiles of interaction partners. We created four profiles ostensibly filled out by single male participants who were senior college students (see online appendix for profile questions). Two critical profiles involved a trade-off between trustworthiness and wealth but were equal in attractiveness. One profile described a man who was trustworthy but not wealthy and another described a man who was relatively less trustworthy but more wealthy. Two filler profiles, which were clearly inferior to the abovementioned profiles, were also created. To make sure that participants never selected the filler profiles, they were undesirable in terms of trustworthiness, wealth, and attractiveness. To reduce suspicion, profiles also included neutral information (e.g., major, favorite book).

Trustworthiness information was manipulated by using a questionnaire that we introduced to the participants as "The Dyadic Trust Inventory," allegedly assessing the extent to which a person can be trusted in their romantic relationships (e.g., "I esteem my partner, shortcomings and all." $1=$ strongly disagree to 7 = strongly agree). Wealth information was manipulated by using two questions. The first question asked participants how many applications they have made to get a job after they graduate and whether they were offered a position. The second question asked participants about their family's monthly income. To indicate attractiveness information, all profiles included a section that was ostensibly filled out by two research assistants who rated participants on attractiveness $(1=$ not at all attractive to $10=$ very attractive).

In the profile that was ostensibly filled out by the trustworthy, not wealthy participant, responses given to the Dyadic Trust Inventory were at the high end of the scale, indicating high trustworthiness. The profile also indicated that the participant had applied to six jobs and got no job offers, and his family had low income, indicating low wealth. In the profile that was ostensibly filled out by the wealthy, untrustworthy participant, responses given to the Dyadic Trust Inventory clustered at the middle of the scale, indicating relatively lower trustworthiness. The profile also indicated that the participant had applied to three jobs and got offers from all of them, and his family had high income, indicating relatively higher wealth.

Laboratory session. Participants were asked to complete a study investigating decision-making processes in interpersonal relationships that consisted of two laboratory sessions: the current session and a second session in which they would interact with a male participant. Participants were informed that there were two conditions in the current study: one group of participants was assigned to an interaction partner, and the other group could choose their partner after reading profiles filled out by potential interaction partners. They were further informed that they had been randomly assigned to the latter condition.

Participants were then given three profiles (two fillers and one of the two critical profiles), which were ostensibly filled out by male participants. They were asked to read through the profiles and to write on a piece of paper the ID number of the person whom they would like to interact with in the next session. After participants notified the experimenter that they made their decision, the experimenter asked them to write down why they made their decision. This procedure was adapted from past work (Dai, Dong, \& Jia, 2014) to increase commitment to the chosen person. When participants handed the three profiles back, the experimenter shuffled through the papers and pretended that she made a mistake: "Oh no, did I give you three profiles earlier? There should have been one more. Sorry about that. If you could please wait for a moment I'll go grab it." The experimenter then left the room and when she returned, she handed back the profile that the participant already selected (the status quo), and the remaining critical profile which was ostensibly forgotten (the alternative). The experimenter asked the participant to carefully review the new profile and to indicate on a piece of paper which of the two men (the status quo or the alternative) they would like to interact with. After indicating their preference, participants were asked to write down why they made their decision. Participants were then informed that they would in fact not be interacting with another participant, were given an apology for the deception, and were fully debriefed.

\section{Results}

Results revealed that of participants whose initial interaction partner was trustworthy (vs. wealthy), a higher proportion preferred trustworthiness over wealth when given an opportunity to switch to an alternative partner (see Table 1). This finding shows that individuals are reluctant to switch to a new alternative even when they have just designated someone as the status quo. Given participants would have very little commitment to a newly designated interaction partner, observing status quo preference under these circumstances provides strong evidence for the robustness of the effect.

\section{General Discussion}

Across seven studies (total $N=1,567$ ), we provided evidence for status quo preference in mate choice and also investigated possible mechanisms and boundary conditions of this effect. In Studies 1 to 3, participants were presented with vignettes involving trade-offs in the three traits central to mate selection decisions - trustworthiness, attractiveness, and wealth - and made a decision about whether to stay in the current relationship or switch to an alternative. In Study 4 , participants were faced with an actual decision between a person they had already selected as their interaction partner 
and a new, alternative interaction partner they were given an opportunity to switch to. In all five studies, we found that preference for a given trait was highest when the individual representing the status quo (i.e., one's current romantic partner or a current interaction partner) was described to have that trait, providing evidence that status quo preference is at play when trading off mate qualities. These findings have important implications for research investigating trade-offs in mate choice. Past work has studied preference for mate qualities by asking participants to decide between two potential mates in the absence of a status quo (Fletcher et al., 2004). The present research demonstrated that the presence of a status quo has a profound influence on the extent to which various mate characteristics are preferred.

Although the status quo preference demonstrated in the present research was sizable (meta-analytic mean correlation coefficient across seven studies was .438), ${ }^{6}$ the effect was eliminated when we created a situation that would reduce commitment to the current partner, that is, when social network members disapproved of the existing romantic relationship and approved of the alternative relationship (Study 2 ). These findings extend past work on social network influence on relationship outcomes by showing that network members play an important role in how individuals resolve mate choice trade-offs. It is possible that other factors, particularly those known to predict relational commitment (e.g., relationship satisfaction; Agnew et al., 2008; Rusbult, 1980), may also affect status quo preference in mate choice, opening up interesting avenues for future work.

Another potentially fruitful direction for future work may be investigating whether social network approval has a similar effect on status quo preference in decision-making domains other than mate selection. For example, if you are contemplating whether to keep your current job or to accept a new job offer, your social network members will likely make their opinions known to you one way or the other. Whether those opinions would affect your preference for keeping your current job - and whether it would affect status quo preference in other decisions - is an open empirical question.

Why are characteristics associated with the status quo preferred over those associated with an alternative? The present study tested potential explanations suggested by relationship and decision-making literatures and showed that at least three factors underlie status quo preference in mate choice (Study 3). One was biased construal of the current partner and the alternative. Individuals showed greater preference for traits associated with the partner to the extent that they evaluated the partner more favorably and the alternative less favorably on unrelated traits. This finding is consistent with research showing that biased construal of options underlies the status quo bias (e.g., Eidelman et al., 2009) as well as research showing idealization of current romantic partners (Murray et al., 1996) and derogation of alternatives (D. J. Johnson \& Rusbult, 1989). Other factors that emerged as probable causes of status quo preference pertained to potential costs of initiating a breakup. To the extent that individuals were concerned about hurting their partner (e.g., Perilloux \& Buss, 2008) and wanted to avoid ambiguities associated with a new relationship (e.g., Berger \& Calabrese, 1975), they showed greater preference for the partner's qualities. Future research should investigate other factors that might potentially predict status quo preference in mate choice. Past work on decision making indicates that the more individuals associate possessions with their sense of self (Dommer \& Swaminathan, 2013) and the more they are emotionally attached to possessions (Shu \& Peck, 2011), the more they exhibit endowment effects. Relationship research too shows that we form strong emotional attachments to our partners (Zeifman \& Hazan, 2008) and construe them as part of who we are (Aron \& Fraley, 1999), pointing to other potential mechanisms that may underlie status quo preference in mate choice.

How can our findings be integrated with extant theories explaining relationship persistence-namely, attachment theory and the investment model? In the current research, status quo preference in mate choice was demonstrated in the context of fledgling relationships (Studies 1-3) and even prior to relationship initiation (Study 4) as opposed to established relationships where issues of attachment and investment are more relevant. Our findings complement existing frameworks by indicating that even in new relationships where affectional bonds are yet to be formed and investments are minimal, it is possible to observe persistence. Would relationship duration affect the magnitude of status quo preference? Attachment theory would predict that in established relationships, status quo preference would even be greater because of strong affectional ties between romantic partners (Zeifman \& Hazan, 2008). The investment model would also make the same prediction but for a different reason. According to this framework, investments in a romantic relationship increase over time as partners spend considerable time together, engage in intimate self-disclosure, and share many facets of their lives including friends, possessions, activities, and memories (Rusbult, 1980), which in turn would make it more difficult to abandon the status quo. Therefore, comparing the magnitude of status quo preference in new versus established relationships would be another interesting direction for future work.

To what extent are the current findings generalizable to real-life interpersonal relationships? Based on research showing that individuals' reports of what they desire in dating partners do not always translate into their decisions following speed dating events (Eastwick \& Finkel, 2008), it is possible to argue that preferences indicated in our vignette studies might not generalize to actual romantic decisions. However, recent evidence showed that self-reported mate preferences are in fact reflected in characteristics of mates in actual romantic relationships (Campbell et al., 2016). Based on this research, one might expect that preferences 
demonstrated in our studies would, at least to some degree, generalize to real-life mating decisions. Moreover, we also provided evidence of status quo preference in an actual decision that participants believed would affect whom they interact with in the future. This situation is similar to choices made in online dating websites where individuals browse through profiles to decide with whom they want to meet. Nevertheless, generalizability of our results to live interactions is limited because participants did not actually meet their potential interaction partners. Would they still prefer the status quo if they encountered potential partners in the flesh? Future research is needed to address this question.

To what extent is status quo preference rational in the context of mate choice? If individuals rationally weighed the importance of various traits and decided accordingly, one might expect them to prefer a given trait to the same extent regardless of whether the trait was associated with the status quo. Our findings showed clearly that this was not the case, thus supporting the claim that mate selection is far from being a rational choice (Gunaydin, Selcuk, \& Hazan, 2013; Inbar, Cone, \& Gilovich, 2010). Perhaps once our fates are intertwined with a potential "soulmate" through unconscious processes such as transference (Gunaydin, Zayas, Selcuk, \& Hazan, 2012) or chance factors such as propinquity (Back, Schmukle, \& Egloff, 2008), we tend to stick with this soulmate regardless of what traits they possess.

On the contrary, status quo preference in mate choice may not only be rational but also be adaptive. From an evolutionary perspective, a so-called bias is functional to the extent that it afforded individuals with survival advantage in our ancestral environment. For example, weighing losses in resources such as food or protection more heavily than gains (loss aversion) served to avoid imminent dangers and hence promoted survival in our ancestral environment (Y. J. Li, Kenrick, Griskevicius, \& Neuberg, 2012). Similarly, status quo preference in mate choice might also be evolutionarily adaptive. Preference for the current partner would help maintain stable pair bonds, which provide better care and protection not only for partners but also for their offspring, thereby promoting survival and reproductive success (Zeifman \& Hazan, 2008). Indeed, it would be irrational to risk the loss of these crucial advantages without the guarantee of a clearly superior alternative partner (Masatlioglu \& Ok, 2005).

Alternative mates might at times be enticing. Despite the constant risk to romantic relationships posed by potential alternative mates and even sensible reasons to end a current relationship (Joel, MacDonald, \& Page-Gould, 2017), most individuals succeed in resisting such temptations. Research shows that the effect of availability of alternatives on breakup is usually small (McKinnish, 2007). But what makes us resist an alternative - even one who might have won out over our present mate if we had been single? The present research suggests that a key factor behind the tendency to preserve one's current relationship is status quo preference. When it comes to matters of the heart, we tend to love what we currently have.

\section{Acknowledgment}

The authors would like to thank Jeremy D. Cone and Eli J. Finkel for their helpful comments on earlier drafts of this article.

\section{Declaration of Conflicting Interests}

The author(s) declared no potential conflicts of interest with respect to the research, authorship, and/or publication of this article.

\section{Funding}

The author(s) received no financial support for the research, authorship, and/or publication of this article.

\section{ORCID iD}

Gul Gunaydin (iD http://orcid.org/0000-0003-0490-4528

\section{Notes}

1. These sample characteristics also apply to Studies 2 to 4 (except that in Study 4, participants completed a laboratory study for course credit).

2. In Study 1a, 1c, and 1d, we repeated the analyses after removing individuals who did not indicate their gender. All findings remained the same as those reported in the results. Gender did not moderate the status quo bias in mate choice in any of the studies (all $p \mathrm{~s}>.333$ ).

3. In all, $95 \%$ confidence intervals for contingency coefficients were estimated using bootstrapping with 1,000 repeated samples.

4. The 2 (current partner: trustworthy vs. attractive) $\times 3$ (social network: approval vs. disapproval vs. no information) $\times 2$ (preference: trustworthy vs. attractive) interaction term was also statistically significant, $G^{2}(7)=53.92, p<.001$.

5. Two participants were extreme outliers on decision time $(6.67$ and 16.33 SD above the mean). Recoding these scores to the next highest value (1.19 SD above the mean) resulted in the same pattern of findings as those reported in the results.

6. The meta-analytic mean effect size was estimated with a random effects model using the procedure recommended by Lipsey and Wilson (2001). The meta-analysis only included comparisons between conditions where a status quo was present and excluded comparisons involving partner approval and disapproval conditions in Study 2.

\section{Supplemental Material}

Supplementary material is available online with this article.

\section{References}

Agnew, C. R., Arriaga, X. B., \& Wilson, J. E. (2008). Committed to what? Using the Bases of Relational Commitment Model to understand continuity and changes in social relationships. In J. P. Forgas \& J. Fitness (Eds.), Social relationships: Cognitive, affective and motivational processes (pp. 147-164). New York, NY: Psychology Press.

Anderson, N. H. (1968). Likableness ratings of 555 personality-trait words. Journal of Personality and Social Psychology, 9, 272279. doi:10.1037/h0025907 
Aron, A., \& Fraley, B. (1999). Relationship closeness as including other in the self: Cognitive underpinnings and measures. Social Cognition, 17, 140-160. doi:10.1521/soco.1999.17.2.140

Back, M. D., Schmukle, S. C., \& Egloff, B. (2008). Becoming friends by chance. Psychological Science, 19, 439-440. doi:10.1111/ j.1467-9280.2008.02106.x

Berger, C. R., \& Calabrese, R. J. (1975). Some explorations in initial interaction and beyond: Toward a developmental theory of interpersonal communication. Human Communication Research, 1, 99-112. doi:10.1111/j.1468-2958.1975.tb00258.x

Buunk, A. P., Park, J. H., \& Dubbs, S. L. (2008). Parent-offspring conflict in mate preferences. Review of General Psychology, 12, 47-62. doi:10.1037/1089-2680.12.1.47

Campbell, L., Chin, K., \& Stanton, S. C. E. (2016). Initial evidence that individuals form new relationships with partners that more closely match their ideal preferences. Collabra, 2(1), 2. doi:10.1525/collabra.24

Campbell, L., Simpson, J. A., Kashy, D. A., \& Fletcher, G. J. O. (2001). Ideal standards, the self, and flexibility of ideals in close relationships. Personality and Social Psychology Bulletin, 27, 447-462. doi:10.1177/0146167201274006

Dai, X., Dong, P., \& Jia, J. S. (2014). When does playing hard to get increase romantic attraction? Journal of Experimental Psychology: General, 143, 521-526. doi:10.1037/a0032989

Davidai, S., Gilovich, T., \& Ross, L. D. (2012). The meaning of default options for potential organ donors. Proceedings of the National Academy of Sciences of the United States of America, 109, 15201-15205. doi:10.1073/pnas.1211695109

Dinner, I., Johnson, E. J., Goldstein, D. G., \& Liu, K. Y. (2011). Partitioning default effects: Why people choose not to choose. Journal of Experimental Psychology: Applied, 17, 332-341. doi:10.1037/a0024354

Dommer, S. L., \& Swaminathan, V. (2013). Explaining the endowment effect through ownership: The role of identity, gender, and self-threat. Journal of Consumer Research, 39, 1034-1050. doi: $10.1086 / 666737$

Eastwick, P. W., \& Finkel, E. J. (2008). Sex differences in mate preferences revisited: Do people know what they initially desire in a romantic partner? Journal of Personality and Social Psychology, 94, 245-264. doi:10.1037/0022-3514.94.2.245

Eastwick, P. W., \& Neff, L. A. (2012). Do ideal partner preferences predict divorce? A tale of two metrics. Social Psychological \& Personality Science, 3, 667-674. doi:10.1177/ 1948550611435941

Eidelman, S., \& Crandall, C. S. (2012). Bias in favor of the status quo. Social \& Personality Psychology Compass, 6, 270-281. doi:10.1111/j.1751-9004.2012.00427.x

Eidelman, S., Crandall, C. S., \& Pattershall, J. (2009). The existence bias. Journal of Personality and Social Psychology, 97, 765-775. doi:10.1037/a0017058

Etcheverry, P. E., \& Agnew, C. R. (2004). Subjective norms and the prediction of romantic relationship state and fate. Personal Relationships, 11, 409-428. doi:10.1111/j.14756811.2004.00090.x

Faul, F., Erdfelder, E., Lang, A. G., \& Buchner, A. (2007). G*Power 3: A flexible statistical power analysis program for the social, behavioral, and biomedical sciences. Behavior Research Methods, 39, 175-191. doi:10.3758/bf03193146

Fletcher, G. J. O., \& Simpson, J. A. (2000). Ideal standards in close relationships: Their structure and functions. Current Directions in Psychological Science, 9, 102-105. doi:10.1111/14678721.00070

Fletcher, G. J. O., Simpson, J. A., \& Thomas, G. (2000). Ideals, perceptions, and evaluations in early relationship development. Journal of Personality and Social Psychology, 79, 933-940. doi:10.1037//0022-3514.79.6.933

Fletcher, G. J. O., Simpson, J. A., Thomas, G., \& Giles, L. (1999). Ideals in intimate relationships. Journal of Personality and Social Psychology, 76, 72-89. doi:10.1037/0022-3514.76.1.72

Fletcher, G. J. O., Tither, J. M., O’Loughlin, C., Friesen, M., \& Overall, N. (2004). Warm and homely or cold and beautiful? Sex differences in trading off traits in mate selection. Personality and Social Psychology Bulletin, 30, 659-672. doi:10.1177/0146167203262847

Gunaydin, G., \& DeLong, J. E. (2015). Reverse correlating love: Highly passionate women idealize their partner's facial appearance. PLoS ONE, 10(3), e0121094. doi:10.1371/journal.pone. 0121094

Gunaydin, G., Selcuk, E., \& Hazan, C. (2013). Finding the one: A process model of human mate selection. In $\mathrm{C}$. Hazan \& $\mathrm{M}$. Campa (Eds.), Human bonding: The science of affectional ties (pp. 103-131). New York, NY: Guilford Press.

Gunaydin, G., Zayas, V., Selcuk, E., \& Hazan, C. (2012). I like you but I don't know why: Objective facial resemblance to significant others influences snap judgments. Journal of Experimental Social Psychology, 48, 350-353. doi:10.1016/j. jesp.2011.06.001

Hainmueller, J., Hangartner, D., \& Yamamoto, T. (2015). Validating vignette and conjoint survey experiments against real-world behavior. Proceedings of the National Academy of Sciences of the United States of America, 112, 2395-2400. doi:10.1073/pnas.1416587112

Hammond, M. D., \& Overall, N. C. (2014). Endorsing benevolent sexism magnifies willingness to dissolve relationships when facing partner-ideal discrepancies. Personal Relationships, 21, 272-287. doi:10.1111/pere.12031

Hazan, C., \& Campa, M. I. (2013). Human bonding: The science of affectional ties. New York, NY: Guilford Press.

Inbar, Y., Cone, J., \& Gilovich, T. (2010). People's intuitions about intuitive insight and intuitive choice. Journal of Personality and Social Psychology, 99, 232-247. doi: $10.1037 / \mathrm{a} 0020215$

Joel, S., MacDonald, G., \& Page-Gould, E. (2017). Wanting to stay and wanting to go: Unpacking the content and structure of relationship stay/leave decision processes. Social Psychological \& Personality Science. Advance online publication. doi:10.1177/1948550617722834

Joel, S., MacDonald, G., \& Plaks, J. E. (2013). Romantic relationships conceptualized as a judgment and decision-making domain. Current Directions in Psychological Science, 22, 461465. doi:10.1177/0963721413498892

Joel, S., Teper, R., \& MacDonald, G. (2014). People overestimate their willingness to reject potential romantic partners by overlooking their concern for other people. Psychological Science, 25, 2233-2240. doi:10.1177/0956797614552828

Johnson, D. J., \& Rusbult, C. E. (1989). Resisting temptation: Devaluation of alternative partners as a means of maintaining commitment in close relationships. Journal of Personality and Social Psychology, 57, 967-980. doi:10.1037/00223514.57.6.967 
Johnson, E. J., \& Goldstein, D. (2003). Do defaults save lives? Science, 302(5649), 1338-1339. doi:10.1126/science.1091721

Kahneman, D., Knetsch, J. L., \& Thaler, R. H. (1991). Anomalies: The endowment effect, loss aversion, and status quo bias. The Journal of Economic Perspectives, 5(1), 193-206.

Li, N. P., Bailey, J. M., Kenrick, D. T., \& Linsenmeier, J. A. W. (2002). The necessities and luxuries of mate preferences: Testing the tradeoffs. Journal of Personality and Social Psychology, 82, 947-955. doi:10.1037//0022-3514.82.6.947

Li, N. P., Yong, J. C., Tov, W., Sng, O., Fletcher, G. J. O., Valentine, K. A., Jiang, Y. F., \& Balliet, D. (2013). Mate preferences do predict attraction and choices in the early stages of mate selection. Journal of Personality and Social Psychology, 105(5), 757-776. doi: 10.1037/a0033777

Li, Y. J., Kenrick, D. T., Griskevicius, V., \& Neuberg, S. L. (2012). Economic decision biases and fundamental motivations: How mating and self-protection alter loss aversion. Journal of Personality and Social Psychology, 102, 550-561. doi:10.1037/ a0025844

Lipsey, M. W., \& Wilson, D. B. (2001). Practical meta-analysis. Thousand Oaks, CA: SAGE.

Masatlioglu, Y., \& Ok, E. A. (2005). Rational choice with status quo bias. Journal of Economic Theory, 121, 1-29. doi:10.1016/j. jet.2004.03.007

McKenzie, C. R. M., Liersch, M. J., \& Finkelstein, S. R. (2006). Recommendations implicit in policy defaults. Psychological Science, 17, 414-420. doi:10.1111/j.1467-9280.2006.01721.x

McKinnish, T. G. (2007). Sexually integrated workplaces and divorce: Another form of on-the-job search. Journal of Human Resources, 42, 331-352. doi:10.3368/jhr.XLII.2.331

Moshinsky, A., \& Bar-Hillel, M. (2010). Loss aversion and status quo label bias. Social Cognition, 28, 191-204. doi:10.1521/ soco.2010.28.2.191

Murray, S. L., Holmes, J. G., \& Griffin, D. W. (1996). The benefits of positive illusions: Idealization and the construction of satisfaction in close relationships. Journal of Personality and Social Psychology, 70, 79-98. doi:10.1037/0022-3514.70.1.79

Perilloux, C., \& Buss, D. M. (2008). Breaking up romantic relationships: Costs experienced and coping strategies deployed. Evolutionary Psychology, 6(1), 164-181.
Rusbult, C. E. (1980). Commitment and satisfaction in romantic associations: A test of the investment model. Journal of Experimental Social Psychology, 16, 172-186. doi:10.1016/0022-1031(80)90007-4

Rusbult, C. E. (1983). A longitudinal test of the investment model: The development (and deterioration) of satisfaction and commitment in heterosexual involvements. Journal of Personality and Social Psychology, 45, 101-117. doi:10.1037/ 0022-3514.45.1.101

Samuelson, W., \& Zeckhauser, R. (1988). Status quo bias in decision making. Journal of Risk and Uncertainty, 1, 7-59. doi:10.1007/BF00055564

Shu, S. B., \& Peck, J. (2011). Psychological ownership and affective reaction: Emotional attachment process variables and the endowment effect. Journal of Consumer Psychology, 21, 439452. doi:10.1016/j.jcps.2011.01.002

Simpson, J. A., Lerma, M., \& Gangestad, S. W. (1990). Perception of physical attractiveness: Mechanisms involved in the maintenance of romantic relationships. Journal of Personality and Social Psychology, 59, 1192-1201. doi:10.1037/0022-3514.59.6.1192

Sprecher, S. (2011). The influence of social networks on romantic relationships: Through the lens of the social network. Personal Relationships, 18, 630-644. doi:10.1111/j.14756811.2010.01330.x

Sprecher, S., \& Felmlee, D. (1992). The influence of parents and friends on the quality and stability of romantic relationships: A 3-wave longitudinal investigation. Journal of Marriage and the Family, 54, 888-900. doi:10.2307/353170

Stafford, L., \& Canary, D. J. (1991). Maintenance strategies and romantic relationship type, gender and relational characteristics. Journal of Social and Personal Relationships, 8, 217-242. doi:10.1177/0265407591082004

Thaler, R. (1980). Toward a positive theory of consumer choice. Journal of Economic Behavior \& Organization, 1, 39-60. doi:10.1016/0167-2681(80)90051-7

Zeifman, D., \& Hazan, C. (2008). Pair bonds as attachments: Reevaluating the evidence. In J. Cassidy \& P. R. Shaver (Eds.), Handbook of attachment: Theory, research, and clinical applications (2nd ed., pp. 436-455). New York, NY: Guilford Press. 